\title{
El Hispanoamericanismo y la Generación del 98
}

ESVANECIDOS los últimos vestigios del gran imperio co-
lonial fundado en América cuatro siglos antes, la España
del 98 se dió cuenta por primera vez de que al fin había esca-
pado de entre sus manos aquel Nuevo Mundo que de ella había
recibido una ley, una lengua, una religión, un arte, en una pa-
labra, todo lo mejor de su cultura del Siglo de Oro. Las hijas
todas habían logrado realizar, al cabo de casi un siglo de lu-
cha, su absoluta independencia política, y ahora, ingratas y
rebeldes, venian reclamando también su independencia cul-
tural y espiritual, ya que el movimiento galicista iniciado cn
Santiago de Chile una década antes, seguía negando cuanto
había de más castizo en el idioma y en la literatura de la
Madre Patria. Sola, abandonada de su prole, en un mundo
moderno hostil a su economía decadente y a su cultura tra-
dicional, España recobró su innato espíritu de lucha, resuel-
ta a volverle la espalda a su glorioso -y fatal- pasado, a
olvidar esos siglos de dominio y de pesadilla y a ganarse otra
vez en la vieja Europa el puesto que había sacrificado al dar
vida a todo un mundo nuevo. Los jóvenes llamados a dar
rumbo a estos impulsos renovadores de la patria constituye-
ron lo que, sólo después de pasada la crisis e iniciado el mo-
vimiento de reconstrucción, uno de ellos, Azorín, acertó en
bautizar con el nombre de la famosa pero, según Baroja, (1)
mítica Generación del 98.

¡Cuán grande fué entonces la sorpresa de España, que es- 
taba decidida a no meterse más en costosas empresas de allende el mar, cuando en la América española brotó el movimiento en pro de la aproximación hispánica! Desaparecida en América la amenaza de una España imperialista, surgió otra más cercana aún, más siniestra, y menos grata — si así se nos permitiera decirlo-, la de una nación joven y poderosa -los Estados Unidos-y de una cultura opuesta en todo a la que recibió la América española de la Madre España. Rubén Darío, el que dió bella e incitadora expresión a estos fervientes sentimientos de raza, cantó para toda Hispanoamérica su confianza y su fe "en el renacimiento de la vieja Hispania, en el propio solar y del otro lado del Océano, en el coro de naciones que hacen contrapeso en la balanza sentimental a la fuerte y osada raza del norte". (2) El miedo al gran "coloso del norte" tuvo sus buenos resultados: lo que España, la Madre, y Bolívar, el Libertador, no habían logrado realizar - la unión espiritual, a lo menos, de las naciones hispanoamericanas-, lo consiguió la amenaza del imperialismo yanqui; pero más significativa aún fué la aparición de todo un grupo de pensadores, poetas y eruditos hispanoamericanos que salieron a reivindicar - no como puros propagandistas del odio a los Estados Unidos, ni como meros políticos partidarios de la hegemonía político-social de la América española, sino como hispanistas sinceros y honestos- la labor de España en América.

Pero de este movimiento en América, de los que lo iniciaron y lo encauzaron, no hay para qué hablar por ser fenómeno sobradamente conocido ya. Lo que más nos interesa ahora es saber cuál fué la reacción de España ante este cambio de actitud de parte de sus desviadas hijas. ¿Cómo recibió la Madre Patria estos gritos de entusiasmado patriotismo racial? $Y$, en particular ¿cuál fué la respuesta de los de la Generación del 98 , los que habían exigido un examen de conciencia, una revisión de valores?

Unos críticos de la literatura contemporánea de España nos darían a entender que fué sólo durante la Guerra Mundial cuando España volvió a interesarse una vez más en sus antiguas colonias, y cuando por primera vez la América española realmente llegó a conocer a la Madre Patria, (3) con- 
cepto erróneo que, en cuanto a la América española a lo menos, ya hemos negado y que en lo que a España toca lo es también, como en seguida pensamos demostrar.

Claro está que hasta cierto punto España se mantuvo en relaciones cuiturales con sus colonias durante todo el siglo XIX - y esto no sólo con las que eran "colonias" en el sentido estricto de la palabra, sino también con las que lo eran todavía desde el punto de vista cultural y espiritual. Prescindiendo aquí de los Mora, Zorrilla, Menéndez y Pelayo, Valera, (4) que, como viajeros y pensadores o como eruditos y críticos, contribuyeron algo al conocimiento de España en América y de América en España, y también de ciertas revistas literarias que, como La América (1857-1870), reunían en sus páginas por largo tiempo el trabajo de españoles y americanos y daban gran ímpetu al mejoramiento de sus relaciones espirituales, lleguemos de un salto a la última década del siglo pasado a ver en qué pie estaban las relaciones entre España y América.

Ya en 1900 señalaba Altamira (a quien con todo derecho debiéramos llamar el historiador de la Generación del 98 y quien hasta hoy mismo (5) ha hecho más que nadie para fomentar mejores relaciones entre España y América) los varios intentos de la década que terminaba por lograr una unión racial más estrecha y más duradera, recordando los Congresos Científicos de 1892, una de cuyas aspiraciones, la de crear un Instituto Pedagógico hispanoamericano, llevaba camino de realizarse cuando Altamira escribía su proyecto de una "Biblioteca de manuales enciclopédicos" con amplia sección americana, y animaba la gestión hecha por la Universidad de Oviedo -en donde enseñaba- y la consignaba en una carta circular enviada a todos los centros docentes y de cultura de América, en que los saludaba "en nombre de la comunidad de raza y de la fraternidad intelectual" y se ofrecía a ellos "para el planteamiento de un cambio efectivo de servicios y de iniciativas en el orden académico..." (6)

Pero de mayor significado que el papel que jugaba España en esas corrientes de aproximación hispánica, eran, según Altamira, las manifestaciones de simpatía que sentían y expresaban las naciones americanas hacia la Madre Patria - y eso 
aún durante "los días luctuosos de nuestra guerra con los Estados Unidos, en que, no obstante la natural simpatía que muchos demócratas americanos sintieron por la causa cubana, no pocos supieron advertir el peligro que entrañaba el excesivo fervor yanqui y separaron discretamente la cuestión política especial que entonces se debatía, del interés general de raza y de civilización, y de los mismos merecimientos de la antigua metrópoli". A ese sentido respondieron varios escritos citados por Altamira: artículos de Darío en La Nación; las conferencias y los discursos de Sáenz Peña en su libro España y los Estados Unidos (Buenos Aires, 1898), y obras y ensayos de Groussac, Tarnassi, Gómez Palacios, Solar, Oyuela, Rodó y otros. Así comenta en parte Altamira el libro de Arreguine titulado En qué consiste la superioridad de los latinos sobre los anglosajones (Buenos Aires, 1900) - en que el autor consigue rectificar con alto sentido crítico y abundante alegación de hechos, el conocido libro de Edmundo Demolins, En qué consisie la superioridad de los anglosajones: “...es como el de Rodó, expresión del espíritu latinoamericano que prevé los peligros de la absorción yanqui... y en este sentido es un nuevo dato de aproximación a España y al espíritu que ésta ha representado y puede aún representar en la historia, una vez purgada de pasados errores e intransigencias..."

La Revista Crítica de Historia y Literatura, que Altamira dirigía, fué portavoz de los que en España anhelaban la hegemonía cultural y espiritual del mundo hispánico. Desde 1895, año de su fundación, hasta 1902, abría sus columnas a todo artículo que abogaba por ese ideal y a reseñas de libros americanos, $\mathrm{y}$ en los artículos de fondo daba apoyo y empuje a la campaña en pro de la raza. Se hace manifiesto el tono militante de la campaña hasta en las reseñas de libros que por su índole científica no le parecerían a uno permitir la introducción del tema. Para J. de Barcelona tales estudios, por ejemplo, El castellano en Venezuela, por Calcaño y Hondureñismos, por Membreño, son de una "significación importantísima... para el porvenir de nuestra raza y de nuestra civilización", porque continúan "el generoso empeño iniciado por Bello y García del Río, de volver 
en lo razonable y posible a la pureza del tronco lingüístico, que no da sólo palabras y reglas de construcción, sino, con unas y otras, ideas, modalidades intelectuales". (7) Aplaude la afirmación del señor Membreño al decir que sólo "los espíritus superficiales" pudieron creer que como resultado del movimiento separatista todo lazo entre España y los pueblos americanos quedaba roto. $\mathrm{Y}$ acoge también con entusiasmo la esperanza manifestada por el señor Latelier, profesor de la Universidad de Santiago, en la creencia de que, "continuando como ha empezado en estos últimos años, el renacimiento científico de España, 'virtualmente establecerá en América una hegemonía intelectual, que por cierto será más provechosa para el mundo que la simple dominación política'," subrayando el consejo de éste al efecto de que "España no deberá olvidar que sólo por el camino de la cultura se logran esos supremos ideales".

Fué Altamira quien dos años después aprovechó la oportunidad que le ofreció el reseñar el Ariel de Rodó, de recordarles a los americanos "el legado valioso que España heredó a las naciones de América", que servía como lazo irrompible para unirlas entre sí y con la Madre Patria, insinuando al mismo tiempo el papel que debía jugar España en la nueva orientación espiritual de América:

“...plantea Rodó el problema de la futura orientación ideal de los hispanoamericanos en términos que nos importa mucho considerar, no sólo porque coinciden con los que aquí señalan todos aquellos que se interesan por el porvenir de nuestras relaciones con América y por la salvación del genio de nuestra raza, sino porque fijan los deberes que toca cumplir a España en la obra de su expansión espiritual y ayudan a la empresa de restauración de los verdaderos hispanófilos que, aquí y fuera de aquí, hace años se empeñan en reivindicar la gloria de nuestro nombre y en que reverdezcan los únicos laureles de que debemos enorgullecernos: los de nuestro espíritu generoso y levantando que, como Ariel, ha persistido aun en medio de las más pesadas esclavitudes impuestas por el grosero sanchismo y ha retoñado siempre por las resquebrajaduras del egoísmo brutal que lo cubre a veces y 
ahora mismo pretende ahogarlo. Ese Ariel... es el nuestro; y colgados de su brazo debemos emprender el camino del mañana juntamente con aquellos a quienes Rodó se dirige, de los cuales podemos invocar, sin arrogancia ni pedantería, el suave imperio que en las inteligencias ejerce la experiencia de una larga historia, de una tradición arraigada a pesar de los vendavales que la combatieron, y de cierta paternidad en que al fin y al cabo, por muchos que hayan sido nuestros desaciertos, pusimos carne de nuestra carne y sangre de nuestra sangre". (8)

La España Moderna también demostraba gran interés por América, dedicando a ella secciones especiales para una revista de su vida económico-política —sección que dirigía Job- y para una galería de "Poetas americanos". Eduardo Gómez de Baquero, que dirigía la "Crónica literaria", daba amplio espacio a los libros de allende el mar. Este interés se acentuaba por los años inmediatamente posteriores a la guerra con los Estados Unidos. Desde las columnas de su crónica, se esforzaba $J o b$ por despertar a las antiguas colonias a la amenaza del peligro yanqui que iba extendiendo sobre toda América su garra imperialista. Cita el "inicuo espectáculo de Cuba miserablemente engañada y sin poder conseguir su independencia", y el caso de los "Canales", que como otras avenidas de entrada para el "coloso del norte" servirían para separar a una parte de la América hispana de la otra. (9) Atribuye el desafecto que alejaba a las colonias de la Madre Patria a la propaganda insidiosa de los imperialistas yanquis: “...en 1892 todavía podía ejercerse en estos países una sugestión contra España en los recónditos pensamientos que se abrigaban de arrojar absolutamente de aquel mundo la bandera de la nación que constituye la cabeza y el vínculo supremo de su raza dominante", pero espera que "después del despojo" las naciones hispanoamericanas se habrán dado cuenta de en dónde yace el verdadero peligro que amenaza romper los lazos que las unen entre sí y con la Madre España. En otro artículo las exhorta a que dicten "la fórmula de la unión" para poder defenderse contra el enemigo común, acabando con estas palabras sugestivas y de gran significación: "Nosotros, que deseamos dar en Madrid el abrazo más 
estrecho a todos nuestros hermanos de América, ¿podremos halagar la idea de que esa fórmula surja en Madrid?" (10)

No faltaban, pues, en la Península, aun desde antes de la Guerra del 98, voces que intentaban animar a la España finisecular a que reconquistara el mundo americano que en aquel entonces se le escapaba rápidamente de la órbita de su poder. Durante la crisis de la guerra misma, hubo quienes quisieron aprovechar la reacción en América hacia la España debatida, denunciando el imperialismo nuevo que les amenazaba más de cerca y sugiriéndoles la conveniencia y la necesidad de una unión sobre la base de irrompibles lazos de sangre y de cultura comunes. Estos deseos de muchos de corresponder al nuevo hálito de espíritu racial que llegaba de allende el mar no se mantenían sólo en el reino de lo ideal: dejando de mencionar los empujes dados al movimiento por el grupo políticoeconómico que muy francamente manifestaba su interés por volver a ganar el mercado americano, basta recordar el Congreso Iberoamericano celebrado en octubre de 1900 en Madrid, en el cual la América y España discutieron las posibilidades de una más estrecha unión económica y cultural. Este asumió para España una importancia casi trascendental cuando el gobierno de los Estados Unidos propuso que se verificara un Congreso Panamericano en México en 1901. La España Moderna (XII, 139, junio de 1900, p. 118) interpretó este acto norteamericano como una táctica política en oposición evidente a los fines que esperaba realizar España con su Congreso Iberoamericano, y se dirigió así a la América hispana:

"Toda la América de nuestra sangre sabe hacia cuál de los dos debe dirigir sus simpatías, y al hacer la acertada calificación del objeto trascendental de uno y otro, sólo muestra vivo temor que el de Madrid, en medio de las expansiones de la fraternidad a que habrá de prestarse, no llene en todo la medida de su verdadera oportunidad e importancia, el fin práctico que todos los clamores solicitan".

El Congreso de Madrid fué un fracaso: de él no salió ningún programa realista ni efectivo. El movimiento entraba de lleno en lo que el Conde de Romanones, presidente del 
Consejo de Ministros, llamó en la sesión del 6 de junio de 1916 "la época romántica" del hispanoamericanismo y que Altamira caracterizó aún más sucintamente como época " «de retórica» a la vez". Así resume éste el rumbo y los resultados del movimiento hasta los años de la Guerra Mundial:

"El romanticismo nos llevó a fundar todas las posibilidades de nuestro prestigio y de nuestra influencia, en motivos sentimentales que no son fantásticos, sin duda, pero que no bastan, ni con ellos solos (máxime si no se les encauza y refuerza) se puede hacer nada de provecho. La retórica nos condujo $\rightarrow$ y puede seguir conduciéndonos - a fiarlo todo en discursos y conferencias, o en exposiciones de programas y de buenos propósitos, como si la palabra fuese ya, por sí misma, acción, y no simplemente anuncio o promesa de acción". (11)

¿Cuál fué la reacción de la América hacia estos intentos de España de identificar una vez más su destino con el de sus antiguas colonias? Veamos lo que de "La Confraternidad hispano-argentina" nos dice Francisco Grandmontagne en un artículo de este título que apareció precisamente en los momentos en que la maternidad de España se había trocado "en una hermandad de cancillería, sin calor espiritual, proclamada por los intelectuales españoles en fríos aluviones de retórica ateneísta, y por el pueblo en gritos de orfeón". (12) Citando a Navarro Ledesma, quien da "prueba de largas vistas" al decir: "Nuestro poder temporal ha cesado; hagamos cuanto nuestras fuerzas permitan para que nuestro prestigio espiritual aumente en los países donde se habla nuestro idioma", afirma Grandmontagne que aquí está el tuétano del problema, porque duda que el actual espíritu español sirva "para influir sobre el espíritu suramericano, empapado, aunque a medias, en el espíritu universal". Es inútil, dice, soñar "con ejercer sobre Sur-América cierta hegemonía espiritual, confiados en que para ello será suficiente el vehículo de la lengua. La influencia por la comunidad de idioma es muy relativa... Necesita España nuevo espíritu... una renovación total en su alma, si quiere entrar con éxito en el concurso europeo, que se disputa la influencia espiritual y económica 
de los pueblos americanos. Necesita España mucha mayor fuerza de la que tiene, y para adquirirla debe ensayar toda clase de recursos, hasta el de guisar los garbanzos con aceite de hígado de bacalao, como dice mi amigo el doctor Severiano Lorente, un médico español que desde la Pampa suele dar a España, en notables folletos, saludables remedios para fortalecerse". $Y$ así contesta a su propia pregunta sobre qué ha hecho España desde que perdió a América, por reconquistar allá el imperio de su espíritu: "Nada: ni lo ha intentado siquiera..." Niega la posibilidad de una hermandad que dé resultados, la eficacia de un movimiento que depende sólo de nexos que tienen su origen en el pasado: "La influencia de España en América tiene que arrancar de un movimiento de progreso español... Más que obra de Gobierno, la expansión española en América tiene que ser obra de la industria y del comercio... Las peluconas, sí, serían un medio excelente de confraternidad o de expansión económica, que es lo que se busca tras de ese ficticio romanticismo fraternal. Influir aquí con oro y con hombres..."

Artículo valiosísimo e interesante en que se valorizan con criterio práctico y sano los esfuerzos de la España de la post-guerra de apoderarse otra vez del mercado americano $\mathrm{y}$ de volver a realizar su antiguo dominio espiritual sobre América: "Pura retórica y motivos mezquinamente egoístas caracterizan estos esfuerzos, pero ni un intento de familiarizarse con la vida de allá y de estudiar los mercados de la América, ni de interpretar y sondear el nuevo espíritu que rige ahora en sus antiguas posesiones. España no ha mandado nunca "un economista, un sociólogo, un hombre de ciencia, un banquero, un escritor de talla, ni siquiera un orador, cuya emigración no se notaría ahí seguramente. Castelar, que tanta oración lírica consagró a Sur-América, columpiándola incesantemente en ondas de éter, fué incapaz de sacrificarle un mareo..." Termina así su crítica mordaz del programa hispanoamericano que España promovía a principios del siglo:

"Una mezquina aspiración comercial ha sido el motor" de todas las expansiones recientes que, si en Madrid han podido tener algún calor, en Buenos Aires, la verdad, han sido 
frías como una nevera... Al español ya no le queda calor más que para hacer notas. Yo no veo en todos vuestros empeños de fraternidad hispano-americana, más que el deseo de asegurar aquí la producción sainetista y dar salida a los pimientos de la Rioja, al aceite andaluz y a los paños catalanes... No censuro yo con esto los empeños de abrir nuevos mercados a los productos españoles... Pero hay que elevar el ideal y poner también más alto el deseo positivo".

Interesante es notar de paso el efecto que produjo sobre los hispanoamericanistas de la Península esta crítica franca de Grandmontagne, quien en conclusión se dirigió a los directores de Nuestro Tiempo - que en esos días acababa de aparecer- indicando que "con sinceridad absoluta y libremente" seguiría hablándoles de América si era su deseo. Busca uno en vano en los números sucesivos de Nuestro Tiempo otros artículos por él firmados - silencio que evidencia, a nuestro parecer, que a los directores les resultó demasiado "sincero y libre" el punto de vista del periodista argentino.

Unos años más tarde Unamuno revela que el hispanoamericanismo es todavía un movimiento que carece de un programa realista y sincero de parte de España, declarando que "es aquí uno de los temas socorridos para discursos tan hueros de pensamiento como de sentimiento". Jamás se cansan de entusiasmarse líricamente por las naciones de origen español, pero si se trata de enterarse de cómo son y viven los americanos, no son capaces de un solo esfuerzo serio. Noticias sobre y de América no llegan al público español, porque "en las redacciones de nuestros periódicos van los periódicos americanos al cesto de los papeles sin haberles siquiera roto la faja. Esto es la verdad y luego hablamos con desdén de todo aquello sin conocerlo". (13)

Que el movimiento perdura, desprovisto de hechos reales y concretos; que la Madre Patria sigue soñando con algo muy vago que bien se pudiera denominar "imperialización de la raza española", sin haberse molestado en averiguar siquiera cómo y hasta qué punto sus antiguas colonias habían cambiado material y espiritualmente como naciones independientes; que se desenvuelve el hispanoamericanismo en ro- 
manticismo y en retórica, hasta después de la Guerra Mundial, ya nos lo indicó Altamira y queda manifiesto también en las observaciones tanto de americanos como de españoles. De Cuba viene este comentario de Arturo R. de Carricarte sobre la ignorancia candorosa - "que mueve a lástima" - con que la mayoría de los críticos españoles se refiere a América, a las cosas de América:

"En el número de La Esfera, correspondiente al 26 de mayo del año en curso, aparece un artículo de don Antonio G. de Linares, ilustrado, entre otros, por dos fotografías que dan la cabal medida del conocimiento que allende el Atlántico se tiene de nuestras cosas. El artículo se titula: 'Por tierras extranjeras... Recuerdos de un viaje a Bolivia' y las ilustraciones a que aludo llevan estas leyendas: una, 'Ruinas incásicas de Uxmal. Puerta del Palacio del Gobernador' y 'Ruinas incásicas de Uxmal. Friso del Palacio del Gobernador'." (14).

$Y$ Carlos Malagarriga pregunta en España: "¿En qué ha venido a parar aquel hispanoamericanismo que hace algunos años pareció que iba a revestir estado político en España y en América?" Apunta algunas notas de actualidad sobre el asunto, concluyendo que a pesar de exposiciones hispanoamericanas, discursos oficiales y llamamientos patrióticos a los: españoles radicados en América, el hispanoamericanismo poco adelanta - "a no ser que le dé algún impulso el viaje de vuelta que algunos centenares de españoles hacen ahora, con viaje abonado por el gobierno argentino que ha creído deber hacer uso -con motivos de las últimas huelgas- del derecho de expulsión que establece la ley de residencia..."! (15)

El movimiento adquiere en España un ímpetu casi épico durante e inmediatamente después de la Guerra Mundial: se multiplican las manifestaciones cordiales; aparecen nuevas revistas dedicadas a divulgarlo y promoverlo. Una de éstas, que prometía mucho por la alta fama de sus colaboradores -ninguno de los cuales, sin embargo, era de la Generación del 98-, fué la fundada en Madrid en enero de 1919 con el título de Raza Española, que aspiraba a ser "revista de España y América". Escritores peninsulares tan ilustres como Bonilla y San Martín, Pardo Bazán y Blanca de los Ríos de 
Lampérez —ésta era la directora- figuran al lado de americanos igualmente distinguidos como Francisco A. de Icaza y José María Rivas Groot. Abundan en ella reseñas y revistas de libros americanos e informes y datos sobre América. El primer artículo, escrito por Jerónimo Bécker, lleva el título militante "La reconquista moral de América". Como modelo muy bello y emocionante del hispanoamericanismo romántico, nada más digno de recordar aquí que el ensayo de la directora que señala el rumbo y el fin del nuevo órgano. Titulado "Nuestra raza", reza en parte:

"Cada vez vemos más claro... que no está completa la mente española sin la mente hispanoamericana; que ni los unos ni los otros podemos revivir aisladamente nuestro pasado, ni podemos historiar nuestra literatura sin historiar entera la de la estirpe, y que como evidencia la crítica literaria del ilustre argentino Calixto Oyucla no se puede ser integramente americano, sin ser integramente español; y yo añadiría que no se puede ser plenamente español sin sentirse juntamente hispanoamericano;... nuestra nacionalidad es una nacionalidad de raza... i Materniclad excelsa de que ningún otro pueblo de la Tierra puede gloriarse, y que prolonga perdurablemente por el mundo americano nuestra vida y nuestra alma españolas! Toda esa gran familia que alienta de nuestro espíritu transfundido en el habla, todo el vasto mundo geográfico que abarcaba en sus grandes síntesis Menéndez y Pelayo, primer español completo, hombre que vivió, pensó y escribió para toda la estirpe, como quien tan bien conocía la génesis y la espiritualidad de toda ella, es nuestra raza... esa unión es ya un hecho de conciencia para los españoles de las dos Españas... claman por la unión de las gentes hispanas, que será la integración étnica y espiritual de ese gran todo, y que en esta hora decisiva de reconstitución mundial deben elegir entre no ser nada, es decir, entre ser una masa amorfa, dispersa y en disolución, destinada a desaparecer de la geografía y de la historia del mundo, o ser la Raza Española una y entera, unida y animada por el insumergible de la más espiritual, gloriosa y magnífica de las lenguas, y llamada a destinos altísimos en un futuro muy cercano". 
Este ideal de "la integración étnica y espiritual" de España y América fué desarrollado más tarde por Luis Araquistain en un ensayo menos lírico pero más profundo titulado "Desintegración en España-Integración en América" (16) que termina con esta frase profética no exenta de toda verdad ni de hondo significado para la Madre Patria de hoy: "La tragedia del español, como conciencia histórica, se resuelve en continuidad y vida en América".

La campaña hispanoamericanista no se mantuvo exclusivamente en este nivel lírico, ni se debe suponer que jamás nacieron de ella consecuencias prácticas y sólidas. Otra vez acudimos a Altamira para ver cuánto fué realmente lo que se resolvió en acción de la campaña verbal. Propulsor y portaestandarte del movimiento desde el principio, Altamira ha sido quien mejor ha comprendido su profundo significado $y$ los muchos problemas que presenta y quien ha insistido siempre en que la "retórica vacía" se convierta en realidad concreta. A él le debemos varios libros en que ha recogido sus muchos discursos y ensayos sobre el tema y en que reúne los datos que nos señalan los hechos prácticos y los resultados tangibles de la campaña. Hay que consultar sus obras España y América, Mi viaje a América, y en particular España y el programa americanista para apreciar mejor los esfuerzos de un pequeño grupo que creía sinceramente que "el hispanoamericanismo no es una aspiración romántica y casi ridícula;... que es posible y lo ha demostrado ya con hechos, y... que España tiene, en su vida actual y en la pasada, muchos títulos para pretender hoy el papel de colaborador digno y útil en la obra de civilización y humanidad que sus hijas (hoy, en muchos casos y por varios títulos, sus hermanas) han emprendido en aquellas tierras de América que siguen nutriéndose con sangre española $\mathrm{y}$ hablan, fundamentalmente, el idioma que es signo en todo el mundo de nuestra unidad y de nuestro espíritu". (17)

A nosotros no nos preocupa por ahora el rumbo que lleva el movimiento desde la Guerra Mundial. Es patente el progreso que España realizó en el campo espiritual respecto a sus relaciones con América. Por la España nueva - la que con sus anhelos democráticos venía acercándose más a Amé- 
rica y que "con la República iba siendo más Madre"-los americanos ya no sentían sólo un amor basado en gran parte en la necesidad de una defensa racial contra el imperialismo del norte, sino una admiración sincera y honda por el espíritu invencible y renovador de la Madre Patria que les servía de modelo. Entonces fué cuando la España renaciente pagó la deuda espiritual que debía a la América que en sus momentos de crisis, allá por el 98, venía a consolar y a animar a la España debatida. Ya no eran sólo los americanos quienes iban a la Península a ofrecer su apoyo a sus hermanos espirituales, sino los jóvenes de la España renacida quienes atravesaban el mar con un mensaje de la patria eterna. Prototipo de aquéllos era Rubén Darío, de éstos García Lorca. (18)

La Guerra Mundial vió nacer una generación que se alejaba radicalmente en todo de la Generación del 98 que por dquel mismo tiempo acababa de llegar al florecimiento pleno de su ideología y de su estética. De 1915 en adelante-con contadas excepciones y sólo en aspectos de poco relieve- los del 98 siguen el rumbo que se habían forjado en las dos décadas anteriores, y contribuirán relativamente poco a la formación de un programa ideológico o estético nuevo. Por eso no nos urge analizar sino su obra y su ideología anteriores a 1918; sólo incidentalmente, y para señalar algún aspecto interesante de su total programa, llamaremos la atención a su producción posterior.

Nosotros no queremos plantear aquí la muy discutida cuestión de quiénes constituyen la llamada Generación del 98. Siendo nuestro deseo principal enfocar la actitud de Unamuno hacia América dentro del cuadro general de su época y de su generación, y no un estudio detenido de la actitud de cada uno de los de aquella época y de aquella generación, nos contentamos con examinar la de unas figuras que indiscutiblemente han sido reconocidas como del 98. Si decimos poco de los poetas y los dramaturgos, es porque o nada revela su obra con respecto al asunto, o lo que dicen no es sino convencional y nada original o indicativo de su propia actitud.

La llegada de Darío a España en 1898 inició el primer movimiento literario verdaderamente hispánico, fraternizán- 
dose desde aquel momento en Madrid por más de una década los modernistas americanos ansiosos de conocer a la Vieja Madre y la nueva generación que le había dado la espalda a la España muerta, unidos no sólo por lazos de raza y de lengua, sino por ser todos "paladines de nuestra muy amada Belleza". Sabido es el lugar que ocupó Darío en esta renovación poética de España; y con él vinieron otros muchos de América que iban a identificarse plenamente con el grupo peninsular.

Donde mejor queda manifiesta esta confraternidad literaria entre España y América es en las dos revistas más importantes que produjo el modernismo en la Península -revistas de corta vida pero de gran significado- que revelan bien lo que era el movimiento en España. Estas revistas son Helios y Renacimiento. La primera apareció en Madrid en abril de 1903 y debe haber terminado con el número correspondiente a marzo de 1904. La segunda salió en Madrid en marzo de 1907, fundiéndose con La Lectura en enero de 1908. Quien desea conocer los aspectos transitorios del modernismo español, o seguir la huella de las corrientes literarias del extranjero, o los orígenes y el desarrollo del movimiento, no puede prescindir de examinarlas. A nosotros ahora nos interesa sólo señalar hasta qué punto modernistas de allende y aquende el Atlántico fraternizaban y colaboraban en ellas.

La redacción de Helios estaba a cargo de Juan Ramón Jiménez, Martínez Sierra, Carlos Navarro Lamarca, Pérez de Ayala y Santiago Pérez Triana. A estos nombres habría que añadir los siguientes como colaboradores: los Quinteros, Benavente, Blanco-Fombona, Darío, Viriato Díaz-Pérez, Angel Guerra, los Machados, Enrique de Mesa, Eça de Queiroz, Rueda, Ugarte, Unamuno, Valera, Carlos Arturo Torres, etc. En Renacimiento, dirigido por Martínez Sierra, colaboraban Darío, Díez-Canedo, José Francés, Gómez-Carrillo, González-Blanco, F. A. de Icaza, Jiménez, los Machados, Marquina, Nervo, Pardo Bazán, Rodó, Rueda, Chocano, Unamuno, Villaespesa, Azorín, Benavente, Menéndez y Pelayo, D’Ors, etc.

Fué en estas revistas en particular y posiblemente - porque no hemos dado con ellas por ninguún lado-en Revista Ibérica y Revista Latina fundadas por Villaespesa -que mu- 
rieron "románticamente una tras otra"-y en Vida Española; Vida Nueva y España Nueva, donde el aspecto lírico y romántico del movimiento hispanoamericano alcanzó la cumbre de su expresión artística. Fué en aquellos momentos del auge de la lira americana en España cuando el mismo Unamuno confesó que "nuestra lengua nos dice desde allende el mar cosas que aquí no dijo nunca".

Entre los poetas de aquella primera década del siglo actual posiblemente nadie simboliza mejor que Martínez Sierra la efusión fraternal que sentían los peninsulares para con sus hermanos de América, y nadie mejor dispuesto ni en mejor posición a fomentar tales sentimientos por ser él entonces director de Helios y de Renacimiento. Pero el amor que proclama es cosa del momento, amor efímero y espontáneo del que así declara lo agradecido que está por el nuevo camino estético que Darío y sus colegas abrieron a la juventud de España. Habla en nombre de todos sus compatriotas cuando en estas palabras reconoce Martínez Sierra la deuda que contrajeron con Rubén:

"España corazón tiene esa deuda de cariño para el poeta americano, como España juventud e intelecto tiene la de ciencia y belleza para el poeta universal. Así, amorosamente, debemos pagar nuestra admiración con palabras enseñadas a nosotros por él, en ritmos aprendidos al sonar de su flauta..." (19)

Rodó es el "amigo lejano" cuyo Ariel ha causado en no pocas almas de la España joven un bien incalculable... "y siempre que palabreramente se hable de puentes de oro sobre el mar, y de misiones de razas, y se junten más o menos sonoramente los nombres de España y América íntimamente... la voz que no miente de la conciencia, dirá el nombre de Rodó como puente real, como lazo fuerte..." (20)

Villaespesa, también ferviente admirador y devoto discípulo de Darío - y después, de otros americanos como Lugones, Herrera y Reissig y González Martínez-, comparte con Martínez Sierra los honores de haber fortalecido los lazos espirituales y estéticos del mundo español. Como portaestandarte del modernismo literario y como maestro de todo 
un grupo de jóvenes de los primeros años del siglo, indudablemente despertó en muchos su entusiasmo por los americanos.

Habría que nombrar un poeta más de aquel entonces por ser su contribución el revelar a España los valores estéticos que les venían en lengua de Cervantes de allende el mar de carácter menos lírico, pero de significado más profundo y más duradero. Nos referimos al ilustre poeta y crítico Enrique Díez-Canedo, quien, además de pagar el homenaje debido a los grandes modernistas de América durante el apogreo del movimiento, se ha dedicado desde aquellos lejanos días a estudiar y a conocer a fondo la literatura americana, hasta taI punto que Onís pudo decir "que es dudoso que haya quien (la) conozca en la medida y con la perfección que él". (21) Su conocimiento de América no era cosa estrictamente literaria; viajó por toda ella, dando conferencias, estrechando viejas amistades y formando nuevas. Era de veras el único embajador espiritual de España en América de la generación que se dió a conocer a raíz de la Guerra del 98. Su labor en pro de la aproximación espiritual de la raza hispánica no se ha manifestado tanto en obras publicadas ni aun tanto en actos públicos quizás, como en el rastro invisible pero imborrable de fraternización que ha caracterizado sus andanzas y sus contactos íntimos con los de América.

Creemos no estar equivocados al aifirmar que del entusiasmo por América de estos tres poetas sólo el de Díez-Canedo era sincero, y como tal, duradero. Con sus primeros éxitos dramáticos Martínez Sierra cambió de xumbo, dedicándose a cultivar la comedia burguesa y olvidándose por completo - aparentemente- de la América, y sólo años después volviendo a acordarse de su existencia material al darse cuenta de que a los "coloniales" les gustaban sus obras. Igual pasó con Villaespesa, pues no se vislumbra en su obra copiosa ni una huella de cuánto pensaba en América o de cómo la apreciaba; sólo que en su caso-y esto mucho después, cuando ya en España poco le estimaban- la descubrió otra vez en varias jiras triunfales que hizo por sus tierras, y agradecido compuso entonces poesías y dramas de temas americanos. 
De hecho, pues, ni con actos concretos - salvo en lo ya mencionado-, ni con la efusión lírica con que en tan bellas muestras de espíritu racial como "Salutación del optimista", "Crónica alfonsina" y "Epitalamio", saludó la trilogía de poetas máximos americanos a la antigua Hispania renacida, correspondieron los poetas del 98 a estas manifestaciones de fraternidad de allende el mar. Admiración sí la sentían por aquellos grandes poetas y prosistas, pero una admiración que les prodigaba como a hermanos espirituales y de sangre nacidos por casualidad en las colonias y no como a hombres representativos de América y de un arte americano. Como prueba de esta actitud ya hemos citado los elogios de Martínez Sierra y sólo conviene recordar ahora un libro como La ofrenda de España a Rubén Darío (Editorial América, 1918). Pero la América-tierra y el hombre-masa americano - como pronto veremos - nunca fueron tenidos en alta estima por los poetas, dramaturgos y prosistas españoles: para ellos esa tierra era inculta, primitiva, bárbara y colonial, y el tipo americano el mismo "indiano" del siglo de la Conquista.

Caso único entre los artistas del modernismo peninsular es el de Valle-Inclán, cuyo arte - y sobre esto están de acuerdo los más de los críticos (22) - arranca en gran parte de su contacto íntimo con la tierra de la América, "feo, católico y sentimental", allá cuando en viaje juvenil a principios de 1892, decidió irse a México... "porque México se escribe con equis", y también de la profunda emoción fraternal que sentía por Rubén - "primitivo y refinado como él, un alma gemela". (23) No sólo en el alma del gran poeta americano, sino también en el suelo de "Tierra caliente" encontró una nota espiritual en completa armonía con su propio ser y con su propia concepción de la vida. Lo que le interesaba de la España tradicional, le interesaba también de la América tropical: "su individualismo irreductible y su tendencia a lo espontáneo. Por eso... se hallaba en tierras de América como en la suya propia". (24) Y a América volvió en años posteriores, para renovar allá su pasión por "la vitalidad primitiva y espontánea de una porción del universo y de la humanidad que aún no había tenido tiempo de falsificarse a sí misma". (25). En 1910, con la compañía de María Guerrexo y Díaz de Men- 
doza, hizo una jira por América pasando por la Argentina, el Paraguay, el Uruguay, Chile y Bolivia, y en 1921, por invitación del Presidente Obregón, volvió al país que años atrás le había ayudado a descubrirse a sí mismo, a dar con el rumbo artístico que seguiría por toda la vida.

A partir de lo que, como neófito, escribiera en México, el tema y la nostalgia que por México en especial sentía, repítense y revélanse a todo lo largo de su producción. En varios cuentos de Femeninas (1895), su primer libro, aparece ya el motivo mexicano, en particular en el titulado "La Niña Chole", que en 1903 volvió a salir ampliado en Sonata de estío, obra que bien pudiera llamarse la primera novela tropical dentro de la estética moderna. Esta fué la obra que sin duda despistó a los críticos en su análisis de la actitud del autor frente a América, obra que para ellos comprobó la fascinación que sobre Valle-Inclán ejerció "el barroquismo de América". Pero, como ya hemos apuntado, este exotismo americano no fué para el español tema meramente literario, sino más bien revelación de una fuerza y de una actitud afines a su propia personalidad. América no significaba, pues, tierra lejana y exótica, de escape romántico o modernista; era, al contrario, un mundo entrañablemente suyo, hecho a "su imagen y semejanza íntima". Sólo así se explican la ironía y la sátira -al exponer el desprecio español de lo americano-que en Tirano Banderas (1926) contrasta tanto con la evocación sentimental de la época de las Sonatas.

Porque es aquí en su "novela de tierra caliente" donde realmente se descubre hasta qué punto la realidad americana era "drama de su propia experiencia", hasta qué punto América -por ser tierra de su raza- le reclamaba la misma crítica patriótica que contra España dirigía. En esta obra, que Mañach interpreta como "el elogio de la América bárbara, la América del pecado original que Valle-Inclán sentía morirse con él,... condensó su visión y su emoción de América".

Entre otros juicios de Tirano Banderas hay uno que nos interesa muy en particular, porque el crítico Antonio Espina se aprovecha de la oportunidad para comparar la "actitud castigadora" (Mañach) de Valle-Inclán con "la grave comedia 
que denominamos linda y diplomáticamente 'hispanoamericanismo'." (26) Así, con la misma franqueza, analiza Espina el hispanoamericanismo allá por los años de 1920 a 1930:

"Valle-Inclán hace ruda disección de la vida -es decir, vivisección - en aquellos países tan repetidamente enjabonados por los profesionales... duchos en toda clase de artepecunias y de hipocresías líricas... audazmente - con alguna exageración convengamos en ello-, expone un punto de vista sobre América que abunda en Europa. Dudoso es que tal punto de vista satisfaga a los americanos. Pero, a mi juicio, esas verdades, aunque sean dichas cuidadosamente, son las que necesitamos conocer en ambas orillas del Atlántico... La verdad de lo que pensamos y sentimos unos y otros, y unos de otros, expuesta con claridad y sin rebozo, es la única que debe de encargarse de estrechar los famosos lazos. $Y$ si ella - la verdad- no fuese capaz de estrecharlos, mejor es que permanezcan flojos".

Vemos, pues, que para Valle-Inclán América no es ni mera cuna de su amigo Rubén, ni tema exótico, ni tierra extraña, sino símbolo vivo de su estética, de su propia vida, y de la España tradicional que hubiera querido ver renacerse. Por ende le hubiera parecido una tontería glorificar el hispanoamericanismo - que sepamos, no se refiere al movimiento ni siquiera en términos despectivos. ¿Cómo hablar de confraternidad hispana cuando existe ya entre los dos mundos un golfo tan inabarcable como el que separa a la España del siglo XX de la España medieval? No "enjabona" a América, pues, porque la comprende y la quiere tanto como la Madre Patria contra la cual dirige su pluma satírica.

Nos conviene ahora pasar a examinar la actitud de los que se suelen considerar "los intelectuales" de la Generación, los preocupados del problema nacional, entre los cuales son Ganivet, Unamuno, Maeztu, Azorín y Baroja los que, respecto al hispanoamericanismo, nos dejan ver más clara su posición.

Uno de los primeros en criticar y condenar el aspecto materialista del movimiento político-económico de fines del 
siglo que tenía como objeto ganar otra vez el poderío comercial de España sobre América, fué Angel Ganivet, quien en lo que iba a ser la "Biblia" de la nueva generación, el Idearium español (fechado en octubre de 1896), se declara opuesto a "todas las uniones iberoamericanas habidas y por haber", (27) afirmando que "en nuestra raza no hay peor medio para lograr la unión que proponérselo y anunciarlo con ruido y con aparato". Además, cree que la única unión posible sería la de una "confederación intelectual o espiritual", pero aun ésta la ve en peligro de no ser realizada por pretender sus compatriotas - amparándose bajo fraseologías patrióticas- buscar un mercado para la producción artística y celebrar tratados de propiedad intelectual, cuando de una sencilla operación de comercio se trata. Rechaza estos intentos de dominación intelectual-utilitaria, inútiles desde luego a causa "de la escasa fuerza expansiva de nuestra producción intelectual". Lo que urge para recuperar el prestigio de España en América es que los españoles tengan "ideas propias para imprimir unidad a la obra" y que las den "gratuitamente, para facilitar su propagación". (28) Se comprende que la realización de la verdadera fraternidad hispana es parte íntegra de su programa para el renacimiento de la patria y no sueño lírico ni ideal irrealizables. Existe ya "una comunidad ideal" entre la Madre Patria y sus antiguas colonias. Para él a lo menos el hispanoamericano no es un extranjero, porque con el hispanoamericano está en comunicación intelectual desde el principio. Se da cuenta de que muchos de sus compatriotas han repetido tanto el mismo concepto, que siente la necesidad de asegurarnos de la sinceridad de su propia afirmación, no queriendo que veamos en ella ningún deseo de "hacer alarde de sentimientos fraternales por el estilo de los que usa un orador o un propagandista para emocionar a su auditorio"!

Así sintetiza lo que a él le parece deben ser la política exterior e interior de España:

"Ni por el Norte, ni por el Occidente, ni por el Oriente, hallará España una promesa de engrandecimiento mediante la acción política exterior... Necesitamos reconstruir nues- 
tras fuerzas materiales para resolver nuestros asuntos interiores, y nuestra fuerza ideal para influir en la esfera de nuestros legítimos intereses externos, para fortificar nuestro prestigio en los pueblos de origen hispánico..."

Denuncia también esa política que, mientras esto escribía, iba apartando más y más de la Madre Patria las pocas colonias que todavía le quedaban, $\mathrm{y}$, en sus ideas constructivas respecto a la política del momento, hace unas sugerencias que parecen igualmente aplicables a las relaciones entre España y las naciones hispanoamericanas independientes tanto de aquel entonces como de hoy en día:

"Así, pues, nosotros no podemos contar con la ayuda de nuestras colonias, y justo es que se sepa que de ellas sólo hemos de recibir el mismo pago que recibimos de las que se emanciparon; sólo podemos aspirar a que el mantenimiento de nuestra dominación no nos cueste demasiados sacrificios, y para ello hemos de abrir un poco la mano: renunciar a la dominación 'materialista', a la que hoy nos condena nuestra postración intelectual, y conceder más importancia que a la administración directa de las colonias por la metrópoli, a la conservación de nuestro prestigio, un tanto quebrantado por las pretensiones egoístas de los detentadores y usufructuarios del poder político.

"Hay quien cree que el término fatal de la colonización es la emancipación de las colonias. A mi juicio este concepto es teórico.

"Si merced a una política hábil, y más que hábil desinteresada, se mantiene la debida unidad de ideas y sentimientos entre una metrópoli y sus colonias, se puede aplicar sin peligro el régimen autonómico, que conducirá, no a la emancipación, sino a la confederación de las colonias autónomas con su metrópoli, y de esta suerte la autonomía no será un primer paso hacia la emancipación: será el comienzo de una unión más íntima, lograda mediante el sacrificio de eso que yo he llamado dominación materialista". (30)

¿Puede que en esto de la autonomía pensara Ganivet ya no sólo en las colonias, sino también en los otros países de 
América independientes desde mucho tiempo antes? Indudablemente que sí, que Ganivet soñaba con una confederación de Estados independientes y autónomos, de la misma lengua y raza, del mismo origen, y de más comunidad ideal aún que la del gran Imperio Británico. Nos inclinamos a esta creencia porque - no sabemos si a sabiendas o no-Ganivet se refiere casi siempre indistintamente a los que todavía eran colonias y a los que llevaban vida independiente por tres cuartos de un siglo, como lo vuelve a hacer, por ejemplo, al final de su discusión sobre la política americana de la patria: “...y así tendremos pan espiritual para nosotros y para nuestra familia, que lo anda mendigando por el mundo, y nuestras conquistas materiales podrán ser aún fecundas, porque al renacer hallaremos una inmensidad de pueblos hermanos a quienes marcar con el sello de nuestro espíritu". (31)

Si algo vagos y confusos suenan estos altos ideales expuestos por Ganivet, mucho más nebulosos son los enunciados por Ramiro de Maeztu en su Defensa de la hispanidad. Aquél al menos avanza unas ideas concretas respecto a la política de la Madre Patria, hacia las colonias que todavía le quedaban en 1896 y propone también algo realizable -aunque altamente quijotesco cuando al mundo hispano se refiere- al sugeriro, o al menos insinuar, la confederación de Estados autónomos hispánicos; pero éste, entusiasmándose con la lectura de la "'Salutación del optimista', único himno hispanoamericano que tenemos", (32) se pone netamente en la categoría de los hispanoamericanistas retóricos al afirmar que lo que más necesitan los pueblos hispánicos es "una norma para el porvenir" que encontrarán en el propio pasado "de la Hispanidad en sus dos siglos creadores, el XVI y el XVII", en la "obra incomparable de ir incorporando las razas aborígenes a la civilización cristiana", añadiendo que "sólo se salvará la Hispanidad en la medida en que sus pueblos se den cuenta de que esa es su misión y la obra más grande y ejemplar que pueden realizar los hombres en la Tierra". (33) Con que se ve que para Maeztu el hispanoamericanismo es un principio vital en su programa de reconstrucción de la patria "territorial y privativa". Se perfilan igualmente las otras facetas de su ideología: la católica, la tradicional-histórica, 
y la aristocrática o "totalitaria" como hoy se dice. Estas se revelan bien a las claras cuando declara: "Nuestra rehabilitación histórica no puede influir directamente sino en la gente culta, en la aristocracia, en la "élite'." (34)

Maeztu acredita a Darío el haber iniciado el movimiento de profunda simpatía racial que el español denomina "Hispanidad", impulso que Rubén "sintió confusamente desde 1898 pero que los españoles sólo vimos muchos años después", (35) que parece indicar que el tipo de hispanoamericanismo que acoge Maeztu es el que tomó forma neta y que cobró ímpetu "alarmante" en el programa de los "nacionalistas" - tipo, desde luego, no aceptado por los de América que, simpatizando con la República, aplaudían su programa de autonomía. En este sentido, pues, Maeztu opta por una política hispanoamericana más de acuerdo con uno de sus aspectos recientes que con la de los primeros años del siglo.

Mientras Maeztu no puede menos de incluir a América dentro de su plan o ideal de la reconstitución del antiguo imperio hispánico, otro de su Generación, que como él vuelve al pasado en donde se sitúa por mejor apreciar así de lejos la España contemporánea, no descubre nada en aquel pasado glorioso de la Conquista que justifique para la futura grandeza de la Madre Patria la restauración de la España Imperial. Puede que fuera más justo decir que aunque lo descubriese, aunque hallara algo eterno en aquel esfuexzo espiritual de la España de la Conquista que pudiera aceptar como bueno e imprescindible para la regeneración de la España moderna, no lo relacionaría con ningún movimiento de raza, ni con la Hispanidad de Maeztu, ni con ningún otro programa hispanoamericanista.

Para Azorín, indudablemente, el papel que hizo España durante la Conquista y la colonización de América no contenía en sí ninguna virtud que hiciera falta a la España del 98. En aquellas páginas de su historia no habría nada que la fortificara ni en el presente ni para el futuro. Aquel momento era sólo y absolutamente del pasado y respecto a él pudo repetir con Costa: "Hay que cerrar con doble llave la sepultura del Cid". 
España y América deben estar en camino de forjar cada una su propio ideal de "perfeccionamiento hacia lo universal humano... y cuanto más trabajen por acercarse a ese ideal, tanto más cerca estarán una de otra, sin que exista propósito de acercamiento... Laboremos, pues, no por un ideal nacional o de 'raza', sino por el alto y exquisito de Humanidad". (36) "Harto vanas y estériles", pues, y "relegadas a segundo plano" le parecen ser "todas las cuestiones del hispanoamericanismo", porque "por encima de las estrechas miras de una nación debemos colocar siempre un concepto supremo: el concepto de Humanidad". No quiere que España cuente con América en su programa de reconstrucción y tampoco que América identifíque su causa con la de la Madre Patria: “...lo que América debe ser y debe querer ser, es un conjunto humano, una masa social, en que se vaya realizando, no tal o cual ideal de afinidad con otras naciones trasatlánticas, sino un ideal alto, noble, exquisito de Humanidad". (37)

América - como parte íntegra de la España gloriosano le interesa, pues, a Azorín; América como entidad humana en su propio derecho, si; pero aun así, juzgando por lo poco que de ella se ocupa en sus obras, le interesa mucho menos que otras naciones. De América habla desinteresadamente, poco y sin dejar vislumbrarse nunca la pasión de los entusiasmados hispanistas.

Los ya citados de la Generación se han preocupado o poco de América, como en el caso de Azorín, o a ella han dedicado insulsas tonadas líricas en elogio de todo lo americano. Sólo Valle-Inclán -y esta actitud suya corresponde a su período literario posterior al de evocación sentimental- presenta a América en una luz desfavorable. Al pequeño anárquico y nihilista Baroja le toca el papel de pintar a los americanos a través de ojos europeos; su concepto y su opinión de ellos corresponden más bien a la actitud general europea que a una convicción sincera y personal: "Yo no tengo motivo particular de odio contra los americanos; la hostilidad que siento contra ellos es por no haber conocido a uno que tuviera un aire de persona, un aire de hombre". (38) Y más tarde confesará: "Tampoco creo que lo que he dicho acerca de los americanos sea estrictamente justo, no. Los hombres 
son iguales en todas partes, en Europa, en América y Oceanía. Lo que a mí me irrita de los hispanoamericanos es lo mal que legitiman su modernidad... Están a la altura de lo peor que hay entre nosotros: del señorito". (39)

Demasiado conocido es el tipo convencional americano de la novela barojiana y nada ganaríamos con intentar retratar el tipo sobre la base de un análisis de los caracteres de sus novelas, tipo, además, que corresponde plenamente a la caracterización del americano que se perfila en sus varios ensayos de índole interpretativa y personal: "tipo petulante, huero, sin una virtud, sin una condición fuerte... uno se nos aparece como un impulsivo atacado de furia sanguinaria, el otro con una vanidad de bailarina, el texcero con una soberbia ridícula". Y así por el mismo estilo cuando de americanos se complace en hablar. E igual o peor su opinión cuando de cultura en general o de letras americanas trata: "Todo lo que he leído de los americanos, a pesar de las adulaciones interesadas de Unamuno, lo he encontrado mísero y sin consistencia. Comenzando por ese libro de Sarmiento, Facundo, que a mí me ha parecido pesado, vulgar y sin interés, hasta los últimos libros de Ingenieros, de Manuel Ugarte, de Ricardo Rojas, de Contreras. :Qué oleada de vulgaridad, de esnobismo, de chabacanería, nos ha venido de América!"

Baroja no puede aguantar las adulaciones "interesadas" de sus compatriotas. Entre los primeros acusa a Unamuno, quien "paralelamente desprecia en sus escritos a Kant, a Schopenhauer y a Nietzsche y elogia al gran general Aníbal Pérez y al gran poeta Diocleciano Sánchez de las Pampas" - elogio que les parecerá poco a "esos rastacueros". (40) Salvador Kueda le parece el epítome de esta efusión racial de parte de España para con América: para Rueda el colmo de la gloria "es entrar en Tegucigalpa triunfante, ser llevado al Casino español y coronado con una corona auténtica de laurel". (41) Pasó a la historia, dice, "la época de la fioritura de los Castelar, de los Labra... pronto pasará la época de los Salvador Rueda, de los Cavestany, de los López Muñoz..." (42) Epoca también de Zamacois y de Villaespesa y de Blasco Ibáñez; (43) época de "Ai, ai, ai. ¡Jaleo! ¡Jaleo! Odas a la Argentina, salutaciones a Chile, Fiestas de la Raza, elo- 
gios a Colón y a su señora madre... (de) discursos, comisiones, banquetes, kilómetros de percalina... Esto es lo que sienten los americanos que se vaya". (44)

Fácil es deducir de esto su opinión del hispanoamericanismo, de esas fiestas que llama "mojiganga iberoamericana". Se burla de los que afirman que "por política" los españoles deben elogiar a los americanos: "Es una de tantas recomendaciones que salen de esos antros de hombres de sombrero de copa y con un discurso dentro que llaman sociedades iberoamericanas". (45) Confiesa francamente que no cree "que esa política tenga eficacia alguna". Le disgusta que tras de esta bandera de hispanoamericanismo sus compatriotas intenten mejorar su situación económica: "Si nuestra banđera no les sirve a los comerciantes españoles de América para vender" tachuelas o latas de conservas, que las vendan con cualquiera otra". Denuncia esos esfuerzos de volver a vivir "con la carga de América"... "Tarde o temprano el pequeño lazo que nos une con América se ha de romper. Cuanto más pronto se rompa, mejor". (46) Y así cuando en un artículo titulado "¿Con el latino o con el germano?" (47) pondera la cuestión de una alianza política internacional, ni siquiera se le ocurre hacer referencia a América; no dice nada respecto a plantear la posibilidad de una Confederación de Estados hispanos autónomos. (48) Verdaderamente, "los españoles de América y los americanos no (le) interesan nada".

$Y$ ahora para terminar - $y$ antes de hablar de su labor como crítico de las letras americanas- nos queda ver lo que pensaba Unamuno de la política hispanoamericanista.

A quien haya leído cuanto ha repetido el filósofo salmantino sobre "la gran patria del espíritu", "la gran «Patria humana»"; a quien conozca de memoria su conocida frase: "la unión fecunda es la unión espontánea" y su "forzada paradoja": "cuanto más se diferencien los pueblos, más se irán asemejando... porque más irán descubriendo la humanidad en sí mismos", no le sorprenderá que Unamuno rechace todo esfuerzo intencionado hacia una mayor aproximación de los pueblos hispanos. Sólo hay que recordar su definición de los tipos de regionalismo que admite: "uno de propietarios, retrógrado, proteccionista, el que pide cruceros, guarniciones, 
limosna de la que mancha y empobrece, y otro que pide que se deje a cada pueblo desarrollarse según él es", para comprender que nunca pudiera haber sancionado una vuelta hacia la política "proteccionista" o interesada de antaño. Sólo hallamos una referencia de Unamuno - a que ya nos referimos- tocante al hispanoamericanismo entre cuanta materia édita e inédita suya nos ha tocado repasar, y es la que emite al reprenderles a sus compatriotas la ignorancia que de América revelan y el desdén con que luego de ella hablan: "Eso de la unión iberoamericana es aquí uno de los temas más socorridos para discursos tan hueros de pensamiento como de sentimiento, mas cuando se trata de enterarnos de cómo sean $\mathrm{y}$ viven las naciones americanas de lengua española, entonces todos nos echamos hacia atrás".

Más fuertes que los nexos políticos o económicos son para Unamuno los que incorporan a los países de América dentro de la gran familia hispánica: la lengua, la religión, y la raza, nexos que no importa cuánto los países se diferencien entre sí y de la Madre Patria y que sirven para demostrar cuán profundas son las raíces que los unen al suelo espiritual de la Hispanidad. Esta convicción es patente en cuanto dice de la literatura hispanoamericana; a causa de ella no le apena a su "corazón milenario" de hispano señalar que "la hispanidad ansiosa de justicia absoluta, se virtió, allende el océano, en busca de su destino, buscándose a sí misma, y dió con otra alma de tierra, con otro cuerpo que era alma, con la americanidad". Y tanto como la España del 98 - sin haber podido negar su pasado- salió en busca de su propio destino nuevo, así también que América - sin negar su herencia hispana- siga buscando el suyo propio.

\section{JOHN E. ENGLEKIRK.}

(1).- "Yo no creo que haya habido, ni que haya, una generación de 1898. Si la hay, yo no pertenezco a ella... No me ha parecido nunca uno de los aciertos de 'Azorín', el bautizador y casi el inventor de esa generación, el de asociar los nombres de unos cuantos escritores a una fecha de derrota del pais, en la cual ellos no tuvieron la menor parte. Ni por tendencias políticas o literarias, ni por el concepto de la vida y del 
arte, ni aun siquiera por la edad, hubo entre nosotros carácter de grupo. La única cosa común fué la protesta contra los políticos y los literatos de la Restauración.

"Una generación que no tiene puntos de vista comunes, ni aspiraciones iguales, ni solidaridad espiritual, ni siquiera el nexo de la edad, no es generación; por eso la llamada generación de 1898 tiene más carácter de invento que de hecho real". Divagaciones apasionadas, Madrid, Caro Raggio, n. d., pp. 27-28.

(2):-Historia de mis libros, p. 20 s.

(3).- -Véase Bell, Contemporary Spanish Literature, New York, Alfred A. Knopf, 1925, p. 30: "The Great War brought about a closer bond between Spanish America and Spain ... South Americans... made the acquaintance of Spain for the first time..."

(4).-No citamos aquí a Clarín por lo mordaz de su crítica de los hispanoamericanos, que más bien retardaba que promovía el mejor entendimiento entre España y las naciones americanas. Es interesante saber lo que pensaba una de las mentes americanas más claras y más prometedoras de hace cuarenta años, Sanín Cano, el distinguido pensador y humanista de hoy, de los trabajos americanistas de Clarín, Menéndez y Pelayo, y Valera. Así avaloraba el colombiano la crítica de éstos en un ensayo titulado "Papel de la literatura en la fraternidad hispanoamericana" que salió en Nuestro Tiempo de Madrid (II, 14 de febrero de 1902, pp. 212-221: "Veamos, para concluir, lo que los escritores españoles han hecho en favor de la fraternidad américo-hispana... Uno de los escritores españoles más leídos en Hispanoamérica desde hace cosa de veinte años, fué Leopoldo Alas... No quiero decir, aunque parece fácil sustentarlo, que su crítica menuda les haya sido perjudicial a las letras americanas; de lo que sí hay constancia inequívocamente, es de que sus crónicas no hicieron nada en beneficio de la amistad que debe unir a españoles y americanos... esos azotes que, con el nombre de Paliques, les aplicaba a los poetas y prosistas de por acá, eran pasto jugoso de malevolencia... en estas azotainas, Clarín, por buscar el gracejo, consentía en que desapareciese su seritido crítico... confundía en un mismo saco las capacidades de los mediocres y los talentos verdaderos... D. Juan (Valera) digamos que peca por el otro extremo. Escribió el elogio de cosas que no lo merecen; popularizó en el continente nombrecillos que apenas tienen derecho a circular dentro del horizonte de su campanario... Con más amor que los anteriores, y, seguramente, con entendimiento más amplio, ha estudiado el Sr. Menéndez y Pelayo momentos determinados de las letras americanas, $y$ ha logrado fijarlos en páginas apreciables. La seriedad y la buena fe de su empresa son digno ejemplo. Ella hará más para estrechar relaciones entre España y la América española que cuanto ha acabado hasta hoy la diplomacia".

(5).-Nada - ni aun la última gran crisis por la cual su patria, y él mismo también, acaba de pasar-le desvía ni le desanima a este in- 
fatigable apóstol de su programa lanzado hace más de 40 años. Hace poco que fundó en París el Institut International d’Études Ibéro-Américaines.

(6).-Véase "España y la literatura sudamericana", en Revista Critica de Historia y Literatura, V, 8-10, ago--oct. de 1900, pp. 358-366. pp. 1-9.

(7).--Revista Critica de Historia y Literatura, III, 1, enero de 1898,

(8).-Ibid., V, 6-7, junio y julio de 1900, pp. 306-309.

(9).-La España Moderna, XII, 137, mayo de 1900, p. 171.

(10).-Ibid., XII, 138, junio de 1900, p. 148.

(11).-España y el programa americanista, pp. 74-75.

(12).-Nuestro Tiempo, I, 9, sept. de 1901, pp. 39-351.

(13).-Véase su crítica de Geografia argentina en La Lectura, VI, 63, marzo de 1906, pp. 332-336.

(14).-Una polémica americanista en España”, Nosotros, XII, 105 enero de 1918, pp. 78-85. Reproducido de El Fígaro de La Habana.

(15).-V, 220, 26 de junio de 1919, pp. 7-8, en su artículo "Cartas de Ultramar. Iniciativas hispanoamericanas".

(16).-España, VII, 298, 15 de enero de 1921, pp. 3-4.

(17).-España y el programa americanista, pp. 74-75.

(18).-Véase el interesante estudio de John A. Crow "Federico García Lorca en Hispanoamérica", en Revista Iberoamericana, I, 2, nov. de 1939, pp. 307-319, quien cita estas palabras de Rafael Maya: "García Lorca renovó el prodigio de Darío, pero al revés. En este caso la influencia vino de España a América. La aparición de Lorca, con todas sus consecuencias intelectuales, guarda un extraño parecido con la de Darío".

(19).-Motivos, pp. 25-29.

(20).-Ibid., pp. 83-86.

(21).-Antologia de la poesía española e bispanoamericana, p. 625.

(22).-Véanse los estudios de M. Fernández Almagro, "Ramón del Valle-Inclán: Vida y obra", Revista Hispánica Moderna, II, 4, julio de 1936, pp. 295-300; de Jorge Mañach, "Valle-Inclán y la elegía de América", Ibid., II, julio de 1936, pp. 302-306; y de Alfonso Reyes, "ValleInclán y América", La Pluma (Madrid), VI, 1923, pp. 30-34.

(23).-Mañach, obra citada, p. 303.

(24). -Ibid.

(25). -Ibid.

(26).-Revista de Occidente, V, 44, feb. de 1927, pp. 274-279.

(27).-Idearium español, Madrid, Victoriano Suárez, 1923, pp. 118. 119.

(28).-Ibid., p. 119.

(29).-Ibid., pp. 39-40.

(30).-Ibid., pp. 142-143. 
(31).-Ibid., pp. 184.

(32).-Defensa de la bispanidad, 2. ed., Madrid, 1935, p. 168.

(33).-Ibid., p. 184.

(34).-Ibid., p. 211.

(35).-Ibid., p. 167.

(36).-Andando y pensando, Madrid, Editorial Páez-Bolsa, 1929, pp. $12 \%, 132$.

(37).-Ibid., p. 126

(38).-Juventud, egolatria, Madrid, Rafael Caro Raggio, 1917, p. 283.

(39).-Las boras solitarias, Madrid, Rafael Caro Raggio, 1920, pp. 98-103.

(40).-Juventud, egolatria, pp. 283-286.

(41).-Ibid., p. 118.

(42). - Las boras solitarias, loc. cit.

(43). - Véase Nuevo tablado de Arlequin, Madrid, Rafael Caro Raggio, 1917 , p. 198, donde dice: "Blasco Ibáñez igualmente no se ha descuidado en dar jabón a los argentinos y en trabajar por la emigración. Para sincerarse decía que el porvenir de España está en Argentina, que es lo mismo que asegurar que el porvenir de Cádiz está en Bilbao, y el de Santander en Cartagena. Además, ségún Bonafoux, Blasco pone debajo de su firma como un título: español-argentino".

(44).-Las boras solitarias, loc. cit.

(45).-Juventud, egolatría, loc. cit.

(46). - Las boras solitarias, loc. cit. 1911)

(47).-Nuevo tablado de Arlequin, pp. 188 ss. (fechado agosto de

(48).-Véase su crítica de Argentina en La Lectura, VI, 63, marzo de 1906. 
